\title{
Family Practice Patients' Attitudes Toward Firearm Safety as a Preventive Medicine Issue: A HARNET Study
}

\author{
Allen F. Shaughnessy, PharmD, Joseph A. Cincotta, $M D$, and \\ Alan Adelman, MD, MSPH, for the Harrisburg Area Research Network (HARNET)
}

Background: Firearm-related deaths are expected to outnumber motor-vehicle-related deaths within the next 5 years. The goal of this project was to document gun ownership and safety habits among patients of family physicians and to determine patients' attitudes toward physician counseling about firearm safety.

Methods: We conducted a cross-sectional survey of patients of 11 family practices affiliated with a research network. Patients (or parents of children) were asked to complete a 23-item questionnaire that asked about gun ownership, storage, sources of information about gun safety, and attitudes about gun safety, and the role of their physician.

Results: of the 1359 questionnaires distributed, 1214 (89\%) were returned. Gun ownership varied by location (urban, suburban, and rural) and ranged from $16 \%$ to $59 \%$. Only $8 \%$ of respondents believed that their physician has a responsibility to discuss firearm safety. Most (91\%) patients did not view their physician as a source of firearm safety information, and only $14 \%$ thought their physician was knowledgeable regarding gun safety. Most gun owners (71\%) did not think they would follow their physicians' advice about gun storage. Most patients (57\%) responded that gun safety should not be discussed during the office visit.

Conclusion: With regard to firearm safety, family physicians lack credibility in the eyes of their patients. These patients do not appear to be receptive to information about firearm safety, and efforts to decrease firearm-related injury might be more effective if focused elsewhere. (J Am Board Fam Pract 1999;12:354-9.)

Injury is the leading cause of death for persons aged 1 to 44 years in the United States. ${ }^{1}$ Firearm-related injuries and motor-vehicle-related injuries make up more than one half of these injury-related deaths. While motor-vehicle-related death is on the decline, deaths caused by firearms are increasing. If current trends continue, the number of firearmrelated deaths will surpass that caused by motor-

Submitted 7 January 1999.

From the Harrisburg Family Practice Residency (AFS), Harrisburg, and the Medical College of Pennsylvania, Hahnemann University School of Medicine (AFS), Philadelphia; the Shepherdstown Family Practice (JAC), Mechanicsburg; and the Department of Family Medicine (AA), Milton S. Hershey School of Medicine, Hershey, $\mathrm{Pa}$. Address reprint requests to Allen Shaughnessy, PharmD, Harrisburg Family Practice Residency, PO Box 8700, Harrisburg, PA 171058700 .

This study was supported, in part, by a grant from the Pinnacle Health System. vehicle crashes by the year 2003, and firearms will become the leading cause of injury-related death. ${ }^{1}$

The medical profession, especially the specialty of family medicine, has embraced injury prevention as a public health issue that can be addressed in the office setting. Various groups have recommended counseling aimed at preventing injuries resulting from motor vehicle accidents, falls, poisonings, burns, and bicycling. ${ }^{2}$ The American College of Physicians and the American Academy of Pediatricians have issued statements saying firearm violence is a public health imperative and urging physicians to inform patients about the dangers of firearms and to advise them on ways to reduce the risk for injury. ${ }^{3,4}$ The American College of Emergency Physicians ${ }^{5}$ and the Eastern Association for the Surgery of Trauma ${ }^{6}$ have issued position papers that focus on support of legislation. The American Academy of Family Physicians ${ }^{7}$ recommends firearms education of both adults and children, particularly in homes where firearms are kept. 
In a survey of 973 pediatricians and family physicians performed by Grossman et al, ${ }^{8}$ however, less than $25 \%$ of pediatricians and $12 \%$ of family practitioners counseled more than $5 \%$ of their patients regarding firearm injury prevention. Most physicians in the survey believed parents would be unreceptive. Similarly, a survey of family practice patients found that only $3 \%$ of respondents ever received counseling from their physician about gun safety.

Several studies have investigated the medical aspects of firearm safety in pediatric practice. Webster and colleagues ${ }^{10}$ queried parents of children in pediatric practices in Maryland and found that gun ownership ranged from $27 \%$ to $53 \%$. Nearly all of the gun owners stated they were willing to follow physician advice regarding gun storage, though most would not be willing to remove guns from their home.

Haught et $\mathrm{al}^{11}$ surveyed parents at four public pediatric clinics in a large metropolitan area to determine their attitudes toward firearm injury prevention counseling. Eighty-two percent of questionnaire respondents indicated they would find information about safe storage of guns helpful or very helpful. Forty-seven percent said they would follow the advice of a health care provider not to have guns in the home, and an additional 37\% reported they would think it over.

Senturia and colleagues ${ }^{12}$ surveyed parents attending 29 pediatric practices in seven states to determine the prevalence of firearms in households containing children. Gun ownership was reported by $37 \%$ of the families, and $13 \%$ of handgun owners reported that their guns were kept loaded and unlocked.

Firearm-related injuries can be divided into three main categories: intentional, self-inflicted, and unintentional. Intentional firearm injury involves an assault by one person on another and accounts for $43 \%$ to $74 \%$ of firearm-related injuries. Self-inflicted firearm injuries usually occur as a result of a suicide or suicide attempt, and unintentional injuries occur by accident. Self-inflicted or unintentional injuries caused by a firearm account for $18 \%$ to $39 \%$ of occurrences. ${ }^{13-17}$ Physician counseling regarding proper storage of guns and ammunition probably would have the greatest impact on preventing these injuries.

The burden of suffering for unintentional firearm injury is similar to that of other accidental injuries now considered public health issues. In 1992, 1409 unintentional deaths and 18,169 suicides occurred with a firearm. During this same time there also were almost 20,000 unintentional nonfatal injuries linked to firearms. ${ }^{18}$ By comparison, bicycle riding results in 1000 deaths and 550,000 emergency department visits, about 12,000 deaths are related to falls, and unintentional poisoning results in 5300 deaths, mostly among adults. $^{2}$

The aim of this study was to document gun ownership and safety habits among patients of family physicians and to determine their attitude regarding the idea of physician counseling about firearm safety.

\section{Methods}

This study was conducted in family practice offices by physicians participating in a single community research network. ${ }^{19}$ The network consists of clinicians from seven practices located in and around Harrisburg, $\mathrm{Pa}$. Five practices are located in suburban or semirural areas, and two practices are located in downtown Harrisburg. Three practices, the urban practices and a suburban practice, serve as training sites for a family practice residency. Because cultural norms and attitudes concerning firearms vary among urban and rural areas, two additional practices located in rural areas distant from the Harrisburg urban area also were used to collect data on patient attitudes.

Participants in this study consisted of visitors to the practice older than 21 years who received care for either themselves or a family member. The questionnaires were distributed to patients during a 2-week period by office staff. Patients were asked to complete the anonymous questionnaires before their visit and to put the completed questionnaire in an envelope that was then placed in a collection box. Those who did not want to participate in the project were asked to place the blank survey form in the envelope and return it to the receptionist.

The 23 items in the questionnaire were taken from previous surveys conducted by Senturia and colleagues $^{12}$ and Webster et al. ${ }^{10}$ These previously validated items were pilot tested using family practice patients before widespread use. The study questionnaire elicited information about gun ownership, storage, and safety instructions. Demographic information was also collected, including 
Table 1. Percentage of Patients Claiming Gun Ownership by Area of Residence.

\begin{tabular}{lrrrrr}
\hline Neighborhood & Rifle & Handgun & BB Gun & Other & Any Gun \\
\hline City & 11 & 9 & 4 & 0.5 & 16 \\
Suburb & 34 & 21 & 16 & 1 & 42 \\
Rural & 51 & 32 & 25 & 2.5 & 59 \\
\hline
\end{tabular}

information about the number and ages of children in the home. Ten items asked the degree to which patients agreed with statements concerning gun safety as a medical issue. Respondents were asked to circle a number on a five-point Likert scale ranging from 1 (agree) to 5 (disagree). For analysis, agreement was considered to be a circled response of 1 or 2 , disagreement was represented by responses 4 and 5 , and a circled response of 3 was considered to be neutral.

Most of the data analysis was done using descriptive statistics. The $t$-test was used for continuous variables, and the chi-square statistic was used for categorical data.

\section{Results}

Of the 1359 surveys distributed, 1214 (89\%) were completed. Area of residence was divided among urban $(18 \%, \mathrm{n}=220)$, suburban $(50 \%, \mathrm{n}=611)$ and rural $(27 \%, \mathrm{n}=327)$. The race of maternal head of household was divided among white $(82 \%)$, African American (14\%), and other (4\%). Fifty percent of households had children in the home under the age of 18 years.

Gun ownership varied widely across practices and geographic location. Gun ownership was reported by $16 \%$ of patients living in an urban area, $42 \%$ of patients living in suburban areas, and $59 \%$ of patients living in rural areas. Gun ownership in the practices corresponded with their locale. Rifle ownership ranged from $11 \%$ to $51 \%$, and handgun ownership ranged from $9 \%$ to $32 \%$ (Table 1 ). Guns could be found in $42 \%$ of households with children.

Areas where family practice patients stored guns and ammunition are displayed in Table 2. Most guns were stored inside the house $(82 \%)$, with the bedroom as the most popular place for gun storage (45\%). Fifty percent of patients reported that ammunition was kept in a locked storage area. Households with children present reported a $42 \%$ gun ownership rate. Thirty-four percent owned a rifle,
Table 2. Storage of Guns and Ammunition.

\begin{tabular}{lclc}
\hline Gun Storage Site & Percent & Ammunition & Percent \\
\hline Bedroom & 45 & Locked & 50 \\
Basement & 17 & Unlocked & 34 \\
Other site inside & 20 & In the gun & 18 \\
Other place & 17 & None & 9 \\
\hline
\end{tabular}

$22 \%$ owned a handgun, and $18 \%$ owned a BB gun. Less than $2 \%$ reported owning some other type of gun.

\section{Patient Attitude Toward Firearm Safety Counseling}

Patient attitudes varied toward firearm safety as a medical issue. Almost all respondents (92\%) disagreed with the statement, "My doctor has a responsibility to talk to me about firearm safety." Only $9 \%$ of respondents selected their physician as a source for information regarding gun injury prevention (Table 3).

Similarly, few participants reported that they had discussed guns or gun safety with their physicians. Only $8 \%$ reported that their physician had brought up the issue, and only $2 \%$ reported that they had ever initiated a discussion of gun safety with their physician. Only $20 \%$ agreed with the statement that "they would be offended if my doctor asked me about gun safety," however. This lack of agreement was similar among gun owners and nonowners.

Respondents were divided in their agreement with the statement, "I am likely to follow my doctor's advice about storing guns." Overall, $40 \%$ agreed with this statement, $34 \%$ disagreed, and $26 \%$ responded neutrally. When analyzed by gun ownership (rifle or handgun only), there were significant differences, with $47 \%$ of nonowners and

Table 3. Sources of Information About Gun Injury Prevention.

\begin{tabular}{lcc}
\hline Source of Information & $\begin{array}{c}\text { Nonowners } \\
(\%)\end{array}$ & $\begin{array}{c}\text { Rifle or Gun Owner } \\
(\%)\end{array}$ \\
\hline Gun organization & 35 & 55 \\
Police & 50 & 32 \\
Friend or relative & 15 & 17 \\
Physician & 11 & 4 \\
Other source & 5 & 11 \\
\hline
\end{tabular}

Note: More than one source could have been chosen. 
$29 \%$ of gun owners agreeing with the statement $\left(\chi^{2}=34.902, P=<.0001\right)$.

Neither gun owners nor nonowners seemed to have much faith in the firearm knowledge of their physicians or responded that gun safety was an appropriate topic during an office visit. Only $14 \%$ of respondents thought that their physician was knowledgeable regarding gun safety, a response rate that was similar among owners and nonowners. About one half ( $47 \%$ ) of the respondents agreed with the statement that, "My doctor doesn't have time to talk to me about gun safety," and 57\% agreed with the similar statement that "Gun safety should not be discussed during my visit since there are so many other things to do."

\section{Discussion}

In this survey of family practice patients, we found that although gun ownership was common in certain settings, few participants in our study seemed to be receptive to the idea of their physician counseling them regarding firearm safety issues. Overall, we found that $40 \%$ of respondents had a firearm in the home, which is consistent with reports from other parts of the country. ${ }^{9,13-16}$ Firearms, especially rifles, were reported in three of five rural households.

Only $4 \%$ of rifle or gun owners named their physician as a source of information on injury prevention. These respondents were much more likely to name a gun organization (55\%) or the police $(32 \%)$ as more suitable sources. Physicians seem to lack credibility in the eyes of gun owners; only $13 \%$ of gun owners agreed that their physician knew what to tell them about gun safety, and about one half of them responded that there was insufficient time during the office visit to discuss these issues.

The percentage of patients reporting that they had discussed guns or gun safety with their physician $(10 \%)$ is similar to that $(11 \%)$ reported in a study of parents of several urban pediatric practices. " Patients did not name their physician as a source of information about gun safety, a finding similar to that of other studies. ${ }^{10,11}$

Only $40 \%$ of our patients stated that they would follow their physician's advice about storing guns. Parents surveyed in two different studies conducted in pediatric practices were much more likely to follow their physician's advice. Haught and colleagues ${ }^{11}$ found that $82 \%$ of parents would perceive as helpful information about the safest way to store guns in the home. Three of four parents surveyed by Webster and colleagues ${ }^{10}$ reported that they would follow a pediatrician's advice to keep guns unloaded and locked. This difference might be due to different perceptions of credibility between pediatric and family practice patients, or it might reflect a difference in advice acceptance between the parents of young children seen in the pediatricians' offices and the wide range of patients of family physicians.

There are several limitations to this study. Data were collected in a three-county area in south central Pennsylvania. Although the patients surveyed came from urban, suburban, and rural populations, their responses could be unique to this area and might not represent the attitudes of patients in other parts of the country.

Questionnaires were distributed with instructions that they be returned regardless of whether they were completed. We did not track the number of questionnaires distributed, only the number of questionnaires returned (both complete and incomplete). It is possible that patients who did not complete the questionnaire could have kept it rather than return it incomplete.

The whole issue of firearms is highly volatile, and many patients had strong opinions about the nature of the questions on the questionnaire as well as a perceived agenda on the part of the investigators. Forty-four of the returned surveys had comments written in the margins (no space was provided for any narrative answers) expressing additional concerns not addressed by the questions.

These written comments fell into three themes. Patients who did not own a gun did not see the relevance of the survey or the issue of firearm safety. Other patients responded that because their physician was too busy to address their medical issues completely in a typical office visit, there was no time for firearm safety issues. Next to the statement, "I have asked my doctor about gun safety at least once," a patient wrote, "it seems like a good idea, but, ironically, I don't know if there will be time today."

The third theme was privacy; firearm safety was most definitely not a medical issue, and gun ownership and storage were therefore not appropriate matters for their physician to discuss. In the words of one patient, "I would not ask my doctor about gun safety or the NRA about my blood pressure." 
The issue of a hidden agenda and privacy reached a crisis stage in one practice located in an extremely rural county. The practice provides the only medical care available for this community, and some patients became concerned that the demographic information collected on the survey - age, race, and education level of the heads of household-would be used to identify and possibly persecute gun owners. After approximately 1 week of data collection, the medical director of the office was approached by a local magistrate, who started the conversation by stating his strong belief in the second amendment to the constitution and suggested that there would be legal ramifications if the survey were continued. Despite the objections of the medical director, the board of directors of the health center voted to discontinue participation in the study.

\section{Conclusions}

At least $65 \%$ of unintentional firearm injuries occur in the home. ${ }^{20}$ There is scant evidence, however, that physician counseling regarding firearm safety is beneficial. No studies have evaluated the effectiveness of counseling on the rate of unintentional injury or suicide.

The results of this study seem to be at odds with efforts of medical associations to increase firearm safety counseling by physicians. Although counseling by physicians regarding gun storage and sometimes gun ownership is recommended by these groups, patients in our study did not appear to be receptive to this information.

In contrast to the results of a study of parent attitudes in pediatric clinic populations, patients in this study, especially those who owned guns, responded that they would not be receptive to physician counseling regarding firearm safety. These findings, combined with the lack of evidence supporting firearm safety counseling, suggest that, rather than trying to convince physicians to talk to their patients about firearms and convince patients to listen to them, efforts to decrease firearm-related injury would be more fruitful if focused elsewhere.

Members of the Harrisburg Area Research Network (HARNET).

Harrisburg Family Practice Center: Joshua Bennett, MD, Susan Herman, CRNP, Julie Larson, MD, MSPH, Paula Mackrides, DO, Geoffrey Margo, MD, PhD, Katherine Margo, MD, Allen F. Shaughnessy, PharmD, Ellen Smith, MD, Daniel Weber,
MD, and Family Practice Residents

Mechanicsburg Family Practice Center: Ann Bogdan, MD, Karen Campbell, MD, Daniel Coller, MD, Gary Luttermoser, MD, Pamela McAninch, CRNP, Kathleen Sempeles, MD, Lisa Stokes, CRNP, Edward Thompson, MD, and Family Practice Residents

Cumberland Family Physicians: Richard Davis, MD, Lisa Davis, MD, Jonathan Tocks, MD

Colonial Park Family Pbysicians: Megan Borrer, MD, Kevin Kelly, MD, Monica Lee, MD

Good Hope Family Physicians: Michael Gawlas, DO, Kenneth Harm, MD, Jane Rowehl, MD, Michael Riggleman, MD, and Cathleen Sangillo, MD

Shepherdstown Family Practice: Elizabeth Alwine, CRNP, Janet Cincotta, MD, Joseph Cincotta, MD, Goeffrey James, MD, Gary Schwartz, MD, Jeffrey Weaver, MD.

The Kline Family Practice Center, the Perry County Health Center, and the Meadow Green Medical Group also participated in this project.

\section{References}

1. Deaths resulting from firearm- and motor-vehiclerelated injuries-United States, 1968-1991. MMWR Morbid Mortal Wkly Rep 1994:43:37-42.

2. Counseling to prevent household and recreational injuries. In: U.S. Preventive Services Task Force. Guide to clinical preventive services. 2nd ed. Baltimore: Williams \& Wilkins, 1996:659-86.

3. Preventing firearm violence: a public health imperative. American College of Physicians. Ann Intern Med 1995;122:311-13.

4. American Academy of Pediatrics Committee on Adolescence: firearms and adolescents. Pediatrics 1992; 89(4 Pt 2):784-7.

5. Firearms. Policy summaries 1997. Dallas: American College of Emergency Physicians, 1997.

6. Violence in America: a public health crisis-the role of firearms. The Violence Prevention Task Force of the Eastern Association for the Surgery of Trauma: J Trauma 1995;38:163-8.

7. Firearm safety: 1995-1996 compendium of AAFP positions on selected health issues. Kansas City, Mo: American Academy of Family Physicians, 1996.

8. Grossman DC, Mang K, Rivara FP. Firearm injury prevention counseling by pediatricians and family physicians. Practices and beliefs. Arch Pediatr Adolesc Med 1995;149:973-7.

9. Goldberg BW, von Borstel ER, Dennis LK, Wall E. Firearm injury risk among primary care patients. J Fam Pract 1995;41:158-62.

10. Webster DW, Wilson ME, Duggan AK, Pakula LC. Patients' beliefs about preventing gun injuries to children. Pediatrics 1992;89(5 Pt 1):908-14.

11. Haught K, Grossman D, Connell, F. Parents' attitudes toward firearm injury prevention counseling in urban pediatric clinics. Pediatrics 1995;96(4 Pt 1): 649-53. 
12. Senturia YD, Christoffel KK, Donovan M. Children's household exposure to guns: a pediatric practice-based survey. Pediatrics 1994;93:469-75.

13. Zavoski RW, Lapidus GD, Lerer TJ, Banco LI. A population-based study of severe firearm injury among children and youth. Pediatrics 1995;96(2 Pt 1):278-82.

14. Emergency department surveillance for weapon-related injuries-Massachusetts, November 1993-April 1994. MMWR Morbid Mortal Wkly Rep 1995;44: 160-3, 169.

15. Firearm-related deaths and hospitalizations-Wisconsin, 1994. . MMWR Morbid Mortal Wkly Rep 1996;45:757-60.

16. Vassar MJ, Kizer KW. Hospitalizations for firearm- related injuries. A population-based study of 9562 patients. JAMA 1996;275:1734-9.

17. Sadowski LS, Munoz SR. Nonfatal and fatal firearm injuries in a rural country. JAMA 1996;275:1762-4.

18. Annest JL, Mercy JA, Gibson DR, Ryan GW. National estimates of nonfatal firearm-related injuries. Beyond the tip of the iceberg. JAMA 1995;273: $1749-54$.

19. Slawson DC, Herman JM, Bennett JH. Single community research networks. The HARNET experience. Harrisburg Area Research Network. Arch Fam Med 1993;2:725-8.

20. Public health surveillance of 1990 injury control objectives for the nation. Morbid Mortal Wkly Rep CDC Surveill Summ 1988;37:1-68.

\section{New!}

\section{Learn how to apply evidence-based medicine skills to your everyday practice.}

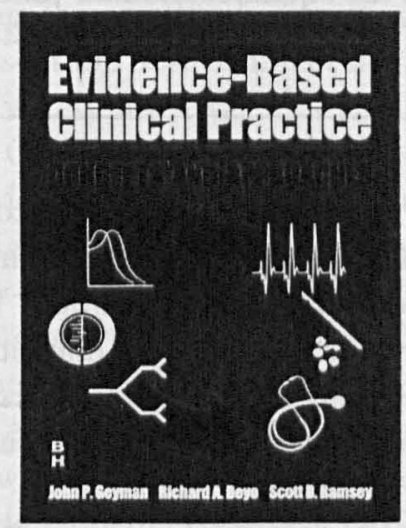

Evidence-Based Clinical Practice: Concepts and Approaches will teach you how to critically read medical literature, develop new skills of self-learning, better evaluate clinical guidelines, understand the techniques and limitations of cost and outcome assessment, and apply the aforementioned skills to clinical practice. This practical text lays the groundwork for understanding an evidence-based approach so you can improve your everyday clinical decisionmaking skills.

- Includes chapters on cost effectiveness in primary care, computer aids to clinical practice, and assessing accuracy of screening and diagnostic tests.

- Provides many patient vignettes, figures and tables to illustrate concepts

- Emphasizes the practical application of evidence-based medicine 